\title{
Genotypes of Giardia lamblia human isolates from Zahedan city, Southeastern Iran
}

\section{Abdolahi Khabisi S. ${ }^{1,2 *}$ Daresh kh. ${ }^{2}$, Salimi Khorashad $\mathrm{A}^{\mathbf{1 , 2}}$}

'Infectious Diseases and Tropical Medicine Research Center, Resistant Tuberculosis Institute, Zahedan University of Medical Sciences, Zahedan, Iran

${ }^{2}$ Department of Parasitology and Mycology, School of Medicine, Zahedan University of Medical Sciences, Zahedan, Iran.

Study Area:Zahedan, Iran

Coordinates: $29^{\circ} 29^{\prime} 47^{\prime \prime} \mathrm{N} ; 60^{\circ} 51^{\prime} 46^{\prime \prime} \mathrm{E}$

Keywords: PCR-RFLP, Giardiasis, Stool test

Ethical Code: Approved by Zahedan University of Medical Sciences' Research Ethics Committee, Zahedan, Iran, conf irmed the present research and procedures under the ethics code of IR.ZAUMS.REC.1397.140.

\section{Introduction:}

Giardia lamblia is considered as one of the major enteric protozoa, which infects many mammalian hosts, including domestic and wild animals, as well as humans (Abbasian et al., 2013, Monis et al., 1999). Thus far, genetic researches using triose-phosphate isomerase (tpi) and the glutamate dehydrogenase (gdh) locus have been identified eight major groups of this parasite in various hosts (Bertrand et al., 2005, Read et al., 2004). A few genotypes were solely identified in particular hosts, but others were determined in a great number of the hosts. In infected humans, A and B genotypes were the two major groups determined using various molecular techniques (Itagaki et al., 2005). These genotypes are not limited to humans, but also have been reported in cats, dogs, and cattle; hence, some studies have approved that giardiasis could be a zoonotic disease transmitted between domestic animals and humans (O'Handley et al., 2000, Traub et al., 2004). Thus far, researchers have shown that sequencing and PCR-RFLP are the two sensitive and powerful methods to differentiate between all genotypes and subgroups of giardiasis (Caccio et al., 2002, Homan et al., 1998). Findings of molecular researches have demonstrated that groups B and A include

\section{$\underline{\text { Abstract }}$}

This study provides the first data on the genotypes of Giardia lamblia which infected people in Zahedan, Southeastern Iran. Samples of stool were obtained from the people infected with giardia. Making use of glass beads, a commercial kit, as well as thawing and freezing methods, from the stool samples, DNA was extracted. Addition, utilizing the Semi-nested PCR, the 432bp fragment of glutamate dehydrogenase (gdh) locus was amplified. Using RsaI and BSPLI restriction enzymes, the RFLP-PCR (restriction fragment length polymorphism-polymerase chain reaction) was carried out to determine the genotypes of the samples infected with Giardia sp. PCR-RFLP demonstrated $77.5 \%$ of the isolates $(n=62)$ as genotype AII and $15 \%$ of the isolates $(\mathrm{n}=12)$ as genotype BIII. In $7.5 \%$ of the isolates $(n=6)$, the mixed genotype (BIII \& AII) was identif ied. The findings of the present study demonstrated that genotype AII led to the majority of human infections in the studied area. According to the obtained results, giardia infection could have an anthroponotic origin in the city of Zahedan, Southeastern Iran.

the subgroups of $\mathrm{B} 1-\mathrm{B} 6$ and $\mathrm{A} 1-\mathrm{A} 8$, respectively. According to past researches on humans, four genotypes of BIV, BIII, AII, and AI were the most common genotypes (CedilloRivera et al., 2003, Monis et al., 1996, Wielinga et al., 2007). Based on the meta-analysis study, the prevalence of giardiasis in different regions of Iran was about $14.7 \%$ (Abbasian et al., 2013). To obtain the sources of human infections in various regions of Iran, it is required that the genotypes of giardia would be properly identified. The molecular genotypes of G.lamblia that infect people in the city of Zahedan, Southeastern Iran, are not clear. Therefore, the present study was conducted on the basis of a seminested PCR assay and PCR- RFLP, making use of glutamate dehydrogenase (gdh) lucus, RsaI and BSPLI restriction enzymes.

\section{Materials and methods:}

Sample collection and microscopic examination: from April 2017 to September 2018, 125 stool samples infected with giardia were taken from individuals who visited the Reference Lab of Zahedan, Southeastern Iran. Written informed consent, as well as demographic data, including sex, age and address, were obtained from the individuals. All samples of stool were examined using both Lugol's iodine 
staining and wet smear techniques under a microscope with the lens of 4ox and 1ox magnification. The samples of stool were kept at the temperature of $-20^{\circ} \mathrm{C}$ before use.

DNA isolation: for molecular analysis 80 stool samples demonstrated at a minimum of 10 cysts in every field with 10x magnifications that were chosen and washed twice using phosphate-buffered saline (PBS), $\mathrm{pH}$ 7.2. To destroy the cyst wall of giardia, the samples were frozen for $5 \mathrm{~min}$ at $-20^{\circ} \mathrm{C}$, and then they were thawed for $5 \mathrm{~min}$ in the boiling water. The freezing and thawing cycles were retried 10 times. Further, $1 \%$ Sodium dodecyl sulfate (SDS), $10 \mu \mathrm{l}$ of Proteinase $\mathrm{K}(10 \mathrm{mg} / \mathrm{ml})$, $200 \mathrm{mg}$ of glass beads $(0.5 \mathrm{~mm}$ diameter) and $500 \mu \mathrm{l}$ of the Gene All Exgene ${ }^{\mathrm{TM}}$ Stool DNA mini kit (South Korea, Cat No: 1151) lysis buffer were provided and vortexed at the highest speed for $5 \mathrm{~min}$. The samples were incubated at $-20^{\circ} \mathrm{C}$ for $10 \mathrm{~min}$ and vortexed two times over the incubation period. Using the guidelines of the Gene All Exgene ${ }^{\mathrm{TM}}$ Stool DNA mini kit, the DNA of each sample of giardia was extracted. The extracted DNA was stored at $-20^{\circ} \mathrm{C}$ before use.

The 432 bp fragment of the gdh lucus was amplified utilizing semi-nested PCR assay. The primers of GDHiR (5' -GTTRTCCTTGCACATCTCC-3'), GDHiF (5' CAGTACACCTCYGCTCTCGG-3'), and GDHeF (5'TCAACGTYAAYCGYGGYTTCCGT-3') were utilized in the semi-nested PCR. In the initial step of the reaction, primers GDHiR and GDHeF were utilized, and in the second step, GDHiR and GDHiF were used. The PCR reaction mixture was comprised of $7 \cdot 5-9 \cdot 5 \mu \mathrm{l}$ of double-distilled water,10 pmol of any of the primers, $1-3 \mu$ l of the DNA template, as well as 12.5 $\mu$ l of Taq $2 x$ Master mix (Amplicon). Utilizing the FlexCycler-2 (Germany) PCR thermal cycler, DNA was amplified as previously described (Read et al., 2004). For both PCR stages, the program was the same. Under red gel staining and on the $1.5 \%$ agarose gel, the PCR outputs were observed.

PCR-RFLP: about $0.5 \mathrm{u}$ of the BspLI (NlaIV, Fermentase) restriction enzyme was utilized to differentiate between groups A, B, as well as giardia isolates' genotypes-A. To differentiate between genotypes BIV and BIII of giardia, the Fast Digest RsaI (Fermentase) restriction enzyme was utilized. The fragments were observed in a $0.5 \mathrm{x}$ TAE buffer on the $2.5 \%$ agarose gel.

\section{Results:}

The semi-nested PCR : by making use of freezing and thawing processes, glass beads, as well as the extraction assay conducted by the Gene All Exgene ${ }^{\mathrm{TM}}$ Stool DNA mini kit, 8o isolates' DNA of 125 positive microscopic samples were amplified. Figure-1 demonstrates the $432 \mathrm{bp}$ fragment of gdh lucus, amplified by using of the semi-nested PCR.

The PCR-RFLP analysis: as per the results of the BspLI restriction enzyme on PCR outputs, a total number of 62 isolates $(77.5 \%)$ were identified as genotype AII with diagnostic fragments, including 123, 87,77, and $69 \mathrm{bp}$. Genotype B was detected in12 isolates (15\%) with 3 diagnostic fragments including 288,123, and 47bp. In 6 isolates $(7.5 \%)$, a combination of groups B and AII was identified. Figure-2 demonstrates the PCR-RFLP results, making use of the BspLI restriction enzyme. Based on PCRRFLP and making use of the RsaI restriction enzyme, all 12 isolates of group B (15\%) demonstrated genotype BIII, revealing the diagnostic fragments of $131,298 \mathrm{bp}$. PCR-RFLP results making use of the RsaI restriction enzyme on the isolates of assemblage B have been shown in Fig.-3. In the present study, just two genotypes of BIII and AII were identified. The demographic information, including sex, age, clinical features and each isolate's genotyping results are shown in Table-1.

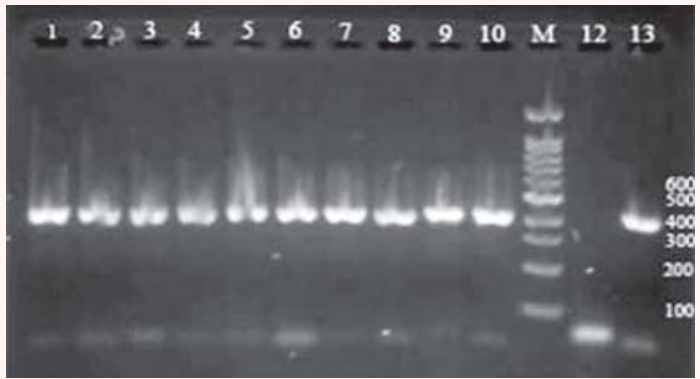

Figure-1: PCR product of 432bp fragments of gdh lucus. Lane 1-10: giardia isolates from the stool of infected humans, lane12: negative control, lane 13: positive control.

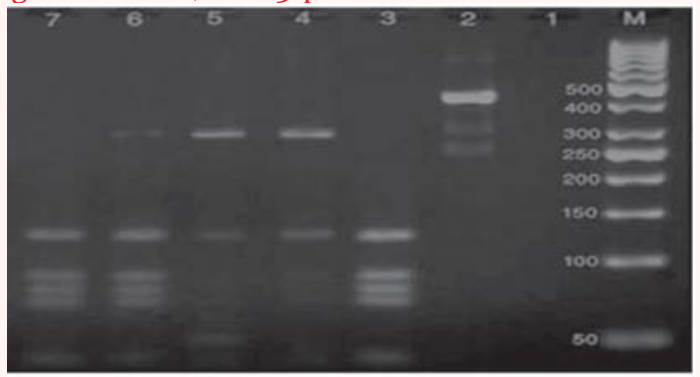

Figure-2: RFLP pattern of PCR products of G.lamblia digested by BSPLI enzyme. M: 50 bp DNA ladder, 2: undigested PCR product for control; lane: 3 \& 7 Genotype-AII, lane: 6 genotype-AII and B and line 4 \& 5 : group B.

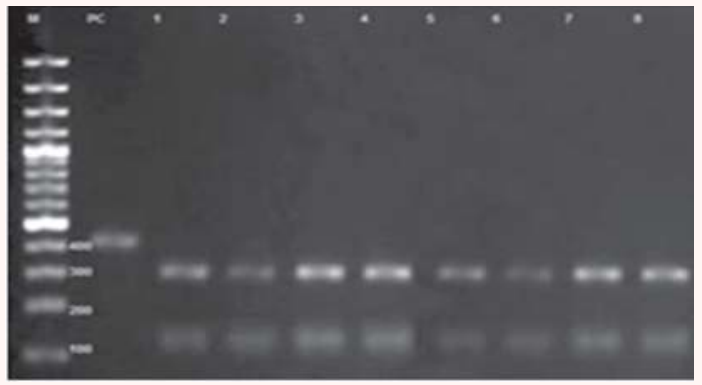

Figure-3: RFLP pattern of PCR products of G.lamblia digested by RsaI enzyme. M: 100 bp DNA ladder, pc undigested PCR product for control, lane: 1-8: Genotype BIII.

\section{Discussion:}

Beside human beings, Giardiasis is one of the major enteric 
protozoa infections of domestic and wild animals in Iran and throughout the world (Flanagan, 1992). Since 2004, the WHO identif ied giardiasis as a neglected disease (Savioli et al., 2006). Molecular researches were conducted on various genes of Giardia lamblia, such as tpi, gdh, and $§$ Giardin, implied the complex nature of this genus. PCR-RFLP, an effective gene-targeting tool, is able to distinguish between the genotypes and assemblages (Amar et al., 2002; Homan et al., 1998; Itagaki et al., 2005; Read et al., 2004). For DNA isolation, in the present work, a mixture of some methods, including the processes of freezing and thawing, SDS and proteinase K treatment and ultimately the stool DNA mini kit were utilized (Babaei et al., 2008). According to the results, the common genotypes of AII and BIII were detected in infected people. The identification of the common genotype of AII in infected people in Zahedan is in line with past researches were done in other regions of Iran. The studies were conducted on the stool samples of 67,44 , 127 and 40 infected people, respectively in Isfahan, the center of Iran (Kashan), the southwestern province of Iran (Fars), implied that genotype AII had a higher prevalence rate than genotype B (Hooshyar et al., 2017; Pestechian et al., 2014; Rayani et al., 2014; Sarkari et al., 2012). Similarly assemblage AII was reported from human isolates of China, Korea, Mexico, and Yemen (Alyousefi et al., 2013; PonceMacotela et al., 2002; Yong et al., 2000). The association between clinical symptoms and genotypes of giardia is controversial. In this present study symptomatic manifestations were found in $30 \%$ of genotype AII, $5 \%$ of genotype BIII and $3 \%$ of mixed genotypes. In this study using Chi- Square statistical analysis test no significant association, was found between genotypes and clinical manifestation in line to other researches in Ahvaz (Rafiei et al., 2013) and southern Iran (Sarkari et al., 2012). The results demonstrated that human infection with giardiasis in the city of Zahedan has an anthroponotic nature. In this study, genotype-BIII was identified in the stool samples of $15 \%$ of the infected people. Genotype BIII has a zoonotic source, yet the present information about this genotype of giardia in animals and livestock in Iran is incomplete. Hence, it is presumed that animals have been the sources of giardia infection in humans in Zahedan. Combined infection with genotype-B \& AII (6.5\%) was identif ied in the isolates of the infected people. Transmission ways could affect mixed infection with giardia. Concludingly, the general finding of this research demonstrated that genotype AII was more common in Zahedan, with the anthroponotic source having been responsible for infections in humans. To determine infection sources, more relevant research should be conducted on animals, humans, and the transmission routes of the infection (Thompson et al., 2004). More comprehensive studies in various regions of Iran are required to access giardia genotypes in animals, humans, and reservoir hosts, so as to identify and address the origins of human infection
Table-1: Frequency of Giardia genotypes in human stool samples based on demographic data.

\begin{tabular}{|c|c|c|c|c|c|}
\hline Parameter & Variable & Freque & of $\mathrm{G}$ & notypes & Total \\
\hline & & AII & BIII & $\operatorname{mix}$ & \\
\hline Sex & Female & 29 & 6 & 2 & 37 \\
\hline & Male & 33 & 6 & 4 & 43 \\
\hline Age & $<10$ & 49 & 8 & 3 & 60 \\
\hline groups & $11-20$ & 7 & 2 & o & 9 \\
\hline & $21-30$ & 2 & o & 1 & 3 \\
\hline & $31-40$ & 1 & o & 1 & 2 \\
\hline & $>40$ & 3 & 2 & 1 & 6 \\
\hline Clinical & symptomatic & 30 & 5 & 3 & 38 \\
\hline features & asymptomatic & 32 & 7 & 3 & 42 \\
\hline
\end{tabular}

Acknowledgment:

We appreciate Vice Chancellor of Research, Zahedan University of Medical Sciences, Iran for the collaboration and financial support of this research. The authors would like also to thank Mr. Rahmati for technical assistance in the molecular work...

\section{References:}

Abbasian, L., Talebi, T., Bazyar, A., Shirbazou, S., Saye Miri, K. \& Ahmadi, N.A. (2013): Prevalence of Giardia lamblia in Iran, a meta analysis and systematic review and meta analysis study. Af. J. Microbiol. Res., 36(5):111-116.

Alyousefi, N.A., Mahdy, M.A., Xiao, L., Mahmud, R. \& Lim, Y.A. (2013): Molecular characterization Molecular of Giardia duodenalis in Yemen. Exp. Parasitol., 134(2):141-147.

Amar, C.F., Dear, P.H., Pedraza-Diaz, S., Looker, N., Linnane, E. \& McLauchlin, J. (2002): Sensitive PCR-restriction fragment length polymorphism assay for detection and genotyping of Giardia duodenalis in human feces. L. Clin. Microbiol., 40(2):446-452.

Babaei, Z., Oormazdi, H., Akhlaghi, L., Rezaie, S., Razmjou, E., Soltani-Arabshahi, S.K., Meamar, A.R. \& Hadighi, R. (2008): Molecular characterization of the Iranian isolates of Giardia lamblia: Application of the glutamate dehydrogenase gene. Iran. J. Public Health., 37(2):75-82.

Bertrand, I., Albertini, L. \& Schwartzbrod, J. (2005): Comparison of two target genes for detection and genotyping of Giardia lamblia in human feces by PCR and PCR-restriction fragment length polymorphism. J. Clin. Microbiol., 43(12):5940-5944.

Caccio, S.M., De Giacomo, M. \& Pozio, E. (2002): Sequence analysis of the beta-giardin gene and development of a polymerase chain reaction-restriction fragment length polymorphism assay to genotype Giardia duodenalis cysts from human faecal samples. Int. J. Parasitol., 32(8):1023-1030.

Cedillo-Rivera, R., Darby, J.M., Enciso-Moreno, J.A., Ortega-Pierres, G. \& Ey, P.L. (2003). Genetic homogeneity of axenic isolates of Giardia intestinalis derived from acute and chronically infected individuals in Mexico. Parasitol. Res., 90(2);119-123.

Flanagan, P.A. (1992). Giardia-diagnosis, clinical course and epidemiology. A review. Epidemiol. Infect., 109(1):1-22.

Homan, W.L., Gilsing, M., Bentala, H., Limper, L. \& van Knapen, F. (1998): Characterization of Giardia duodenalis by polymerasechain-reaction fingerprinting. Parasitol. Res., 84(9):707-714.

Hooshyar, H., Ghafarinasab, S., Arbabi, M., Delavari, M. \& Rasti, S. (2017): Genetic Variation of Giardia lamblia Isolates from Foodhandlers in Kashan, Central Iran. Iran. J. Parasitol., 12(1):83-89. 
Itagaki, T., Kinoshita, S., Aoki, M., Itoh, N., Saeki, H., Sato, N., Uetsuki, J., Izumiyama, S., Yagita, K. \& Endo, T. (2005): Genotyping of Giardia intestinalis from domestic and wild animals in Japan using glutamete dehydrogenase gene sequencing Vet. Parasitol., 133(4):283-287.

Monis, P.T., Andrews, R.H., Mayrhofer, G. \& Ey, P.L. (1999): Molecular systematics of the parasitic protozoan Giardia intestinalis. Mol. Biol. Evol., 16(9):1135-1144.

Monis, P.T., Mayrhofer, G., Andrews, R.H., Homan, W.L., Limper, L. \& Ey, P.L. (1996): Molecular genetic analysis of Giardia intestinalis isolates at the glutamate dehydrogenase locus. Parasitology, 112(1):1-12.

O'Handley, R.M., Olson, M.E., Fraser, D., Adams, P. \& Thompson, R.C. (2000): Prevalence and genotypic characterisation of Giardia in dairy calves from Western Australia and Western Canada. Vet. Parasitol., 9o(3):193-200.

Pestechian, N., Rasekh, H., Rostami-Nejad, M., Yousofi, H.A. \& Hosseini-Safa, A. (2014): Molecular identification of Giardia lamblia; is there any correlation between diarrhea and genotyping in Iranian population? Gastroenterol. Hepatol. Bed Bench., 7(3):168-172.

Ponce-Macotela, M., Martinez-Gordillo, M.N., Bermudez-Cruz, R.M., Salazar-Schettino, P.M., Ortega-Pierres, G. \& Ey, P.L. (2002): Unusual prevalence of the Giardia intestinalis A-II subtype amongst isolates from humans and domestic animals in Mexico. Int. J. Parasitol., 32(9):1201-1202.

Rafiei, A., Roointan, E.S., Samarbafzadeh, A.R., Shayesteh, A.A., Shamsizadeh, A. \& Borujeni, P.M. (2013): Investigation Southwest of Possible Correlation between Giardia duodenalis Genotypes and Clinical Symptoms in Iran. Iran. J. Parasitol., 8(3):389-395.
Rayani, M., Zasmy Unyah, N. \& Hatam, G. (2014): Molecular Identif ication of Giardia duodenalis Isolates from Fars Province, Iran. Iran. J. Parasitol., 9(1):70-78.

Read, C.M., Monis, P.T. \& Thompson, R.C. (2004): Discrimination of all genotypes of Giardia duodenalis at the glutamate dehydrogenase locus using PCR-RFLP. Infect. Genet. Evol., 4(2):125-130.

Sarkari, B., Ashrafmansori, A., Hatam, G.R., Motazedian, M.H., Asgari, Q. \& Mohammadpour, I. (2012): Genotyping of Giardia lamblia isolates from human in southern Iran. Trop. Biomed., 29(3):366-371.

Savioli, L., Smith, H. \& Thompson, A. (2006): Giardia and Cryptosporidium join the 'Neglected Diseases Initiative'. $\underline{\text { Trends }}$ Parasitol., 22(5):203-208.

Thompson, R.C. \& Monis, P.T. (2004): Variation in Giardia: implications for taxonomy and epidemiology. Adv. Parasitol., 58: 69-137.

Traub, R.J., Monis, P.T., Robertson, I., Irwin, P., Mencke, N. \& Thompson, R.C. (2004): Epidemiological and molecular evidence supports the zoonotic transmission of Giardia among humans and dogs living in the same community. Parasitology, 128(3):253-262.

Wielinga, C.M. \& Thompson, R.C. (2007): Comparative evaluation of Giardia duodenalis sequence data. Parasitology, 134(2):17951821.

Yong, T.S., Park, S.J., Hwang, U.W., Yang, H.W., Lee, K.W., Min, D.Y., (2000): Genotyping of Giardia lamblia isolates from humans in China and Korea using ribosomal DNA Sequences. J. Parasitol., $86(4): 887-891$. 